\title{
El teatre italià en les traduccions de Narcís Oller: Giacosa, Rovetta i Goldoni*
}

\author{
Gabriella Gavagnin
}

Al llarg de la primera decada d'aquest segle, Narcís Oller va dedicar-se, amb interès creixent, a la traducció d'obres teatrals. Entre aquestes, tenen un especial relleu les que va fer de l'italià, tant en sentit cronològic, ja que en representen el primer bloc, com pel que fa a la seva projecció escènica i a la seva difusió. Més concretament, Oller va dur a terme entre 1905 i 1908 la traducció de set textos de teatre italià: tres drames burgesos de Giuseppe Giacosa (Com les fuIles, Tristos amors i El més fort), un melodrama de Girolamo Rovetta (Papà Ministre) i tres comèdies de Carlo Goldoni (El Vano, El sorrut benefactor i L'avar). Als anys següents, entre el 1908 i el 1913, va continuar la seva tasca de traductor teatral triant preferentment textos d'autors russos, com Turguenev, Tolstoi o Ostrovski.

En principi, la feina de traductor no deixava de ser per a Oller més una activitat de lleure, sovint reservada per a les vacances d'estiu a Puigcerdà, que no pas una tasca compromesa comparable a la feina de novel.lista. Per això mateix, la traducció podia constituir, en períodes de crisi literària, una alternativa consoladora i menys feixuga. Per exemple, les traduccions de proses russes realitzades el 1897 havien estat, tal com Oller mateix afirma en les seves Memòries literàries, una manera "per distreure ma tristesa i enyorança» (Oller, 1962, p. 235) arran de la pèrdua de Josep Yxart. Deu anys més tard, la contraposició entre creació i traducció, segons testimonia la correspondència amb Francesc Matheu, arriba a delinear-se més netament. En una carta del 2 de setembre de 1907, Oller acaba considerant la traducció gairebé com a últim desesperat refugi en un moment de crisi literària. Ara, però, ja no es tracta d'una crisi creativa causada per motius personals, sinó més aviat d'un sentiment de derrota i de desencant davant la falta de connexió amb el públic:

El meu temps ja ha passat. Déixam llegir, déixam traduhir, deixam veure si en les traduccions trobo un filó més práctic pera explotar a’n aqueix públich

* Aquest treball ha estat realitzat en el marc del Projecte: Catálogo histórico y crítico de las traducciones de obras literarias italianas al castellano y al catalán DGICYT (PB94-0902), dirigit per María de las Nieves Muñiz Muñiz. Vaig llegir-lo com a comunicació al Col.loqui Narcís Oller (Valls, 28-30 de novembre de 1996). 
que no he sabut guanyarme. [...] No m'ho tornis aconsellar may més que produheixi: déixam fer marqueteria y mercadejarla que som en terra de mercaders. / Per això m'he passat l'Agost treballant lo de Paris, fent una traducció d'en Rovetta y preparantme per ferne una del Pane altrui ${ }^{1}$ y una altra d'un drama qu'está acabant en Paulousky pera veure si les faig passar al Principal (Puigcerdà, 2 de setembre de 1907).

Són paraules francament molt dures, sorgides d'un estat de depressió, paraules amb què es desmereix, sense atenuants, el valor literari de la traducció, tot col-locant-la en un restringit horitzó de consum. No serà pas aquesta, però, la manera com Oller descriurà, a posteriori, els seus deu anys de dedicació a la traducció teatral. En veure en retrospectiva la feina feta, plena d'entrebancs però també de grans èxits, ja no li va semblar un conjunt de productes per mercadejar, sinó que li va atorgar una funció cultural específica i la va definir com una tasca patriòtica, com un veritable servei a les lletres catalanes. Amb aquest afany de buscar-hi un sentit global, Oller va explicar i rellegir la seva activitat de traductor a les Notes per a les Memòries del meu pas pel teatre català, que van ser redactades entre els anys 1911 i 1913 i que van romandre inèdites. ${ }^{3}$ Amb un to d'entusiasme i satisfacció, hi construeix la imatge d'un traductor que, per una banda, actua guiat pel seu propi criteri, més enllà de les demandes de mercat ${ }^{4} \mathrm{i}$ amb l'objectiu d'enriquir el teatre català amb obres universals, i per l'altra veu premiat els seus esforços amb molts elogis de la crítica i amb una excel-lent acollida de públic. Vegem, per exemple, el que diu a propòsit de les obres de Giacosa. Si es decideix a traduir al català el Come le foglie és, escriu Oller,

ab l'intenció d'incorporarlo dins, naturalment, dels límits que la meva tasca m'ho podés permetre, al tresor de nostres lletres (p. 1).

1. Es tracta del drama de Turguenev que va ser estrenat per les companyies italianes al tombant de segle (cf. Bonzi-Busquets, 1995, p. 230-234). Oller devia començar a traduir-lo des de la versió italiana, encara que també és possible que més endavant n’aconseguís la traducció francesa, després d'haver-la demanada insistentment a Alfons Maseras; tot i així, en una carta, datada el 13-XII-1910, aquest li escrivia que encara no l'havia poguda trobar (cf. Corretger, 1995, p. 70).

2. Les cartes d'Oller a Francesc Matheu es guarden a la Biblioteca de Catalunya, Ms. 2209VIII, núm. 1015-1175.

3. L'autògraf es guarda a la Biblioteca de Catalunya, Ms. 1920.

4. Oller no solia traduir per encàrrec. Les dificultats econòmiques derivades de la poca rendibilitat del mercat teatral en català el van implicar, però, en primera persona quan va veure perillar la representació del Papà ministre de Rovetta, ja que l'empresari del Principal no volia arriscar-se anticipant-ne els drets a l'autor. Seguint el suggeriment de l'actor Enric Borràs, Oller va traduir l'obra també al castellà, amb l'esperança de poder cobrir els costos en català amb els beneficis de les representacions que Borràs havia promès fer a Espanya i a Sudamèrica. Fins i tot va anticipar ell mateix els drets a Rovetta perquè el Principal es decidís a muntar l'obra. Tanmateix, segons informa Oller a les seves Notes, ni les promeses de Borràs es van complir ni va ser necessari econòmicament, ja que els beneficis que es van aconseguir amb les representacions catalanes van cobrir amb escreix els costos. 
Aquesta mateixa intenció literària, segons explica més endavant, també presidia les traduccions que, arran de l'èxit de crítica, van donar continuïtat a la primera temptativa i la van transformar en un projecte més ambiciós:

Els elogis que prodigá la prempsa a la meva traducció de "Come le foglie» van animarme a dur a nostres lletres altres mostres d'obres capdals del teatre extranger. Posat ja a traduhir en Giacosa, vaig voler començar aquesta tasca portanthi dues obres més del seu teatre modern: «Tristi Amori» y «Il piu forte» (p. 6).

Val la pena notar que Oller no s'oblida de definir «modern» el teatre de Giacosa, amb l'intent de remarcar justament la modernitat de les seves opcions. ${ }^{5}$ Anàlogament, també destacarà la gran actualitat del drama de Rovetta que l'amic Gelormini li va enviar des d'Itàlia tot just acabat d'aparèixer en una revista romana. ${ }^{6}$ Tot plegat, es tracta d'una versió força diferent de la que li havia donat, a cop calent, des de Puigcerdà, a Francesc Matheu a la carta ja citada. És evident que les traduccions d'Oller, més enllà dels motius psicològics i personals que les van ocasionar, tenien efectivament el valor d'una experiència col-lectiva i no pas individual ni privada. D'això, però, Oller no n'era conscient des d'un bon principi i se'n va anar adonant a mesura que la crítica anava destacant el seu paper i el seu servei com a traductor. Per posar un exemple, la ressenya de Joan Avinyó a Com les fulles, publicada a la revista El Poble Català (7 de novembre de 1905), comença amb aquesta lloança:

L'Oller ha fet un bon servei a les lletres catalanes traduint aquesta hermosa comedia den Giacosa, una de les més fortes del modern teatre italià, que ja conta $\mathrm{ab}$ tantes obres mestres.

Un leit motiv que es va repetir puntualment en gairebé totes les crítiques que la premsa va dedicar a les seves traduccions. I no tan sols la premsa. Víctor

5. Els Tristi amori (estrenat a Itàlia el 1887) havia estat el primer gran èxit de Giacosa i pertenyia a una fase de la seva producció en què encara no havia explorat les tècniques del teatre psicològic de matriu ibseniana, però a Barcelona s'havia donat a conèixer juntament amb Come le foglie, durant la primera campanya de Teresa Mariani. En canvi, Il più forte (estrenat a Itàlia el 1904) va ser l'últim drama que va escriure Giacosa, seguint els plantejaments experimentats a Come le foglie. La traducció d'Oller no es va arribar a representar. A la ressenya que li dedica De Tots Colors, 14 (3-IV-1908), signada per Atxa [Joan Oller i Rabassa], s'assenyala que l'obra no és adequada a la representació: «Sens dubte El més fort no es una obra molt escènica y'ns arrisquem a dir que portada a les taules no sería pas un èxit de públich" (p. 216).

6. Així ho explica Oller a les Notes: «El meu bon amich Gelormini, enamorat de la meva traducció catalana de Com les fulles y Tristi amori, pel juliol de 1907 va enviarme els n.os de la revista romana la Nuova Antologia ahont acabava de publicarse l'últim drama de Rovetta "Papá Eccellenza» encarintme les seves belles condicions dramátiques y el gran éxit qu'havia obtingut en el Teatre Argentina de Roma, representat per en Ferruc[c]io Caravaglia. Vaig llegirlo a Puigcerdá y m’agradá tant que’l vaig traduhir tot seguit sense ni tenir a máll més petit vocabulari de que auxsiliarme» (p. 18). 
Català, en rebre el seu segon volum de Goldoni, també es feia ressò d'aquest elogi esdevingut tòpic:

Lo Sorrut benefactor és molt simpàtic, lo mateix que l'Avar, i més simpàtic encara el traductor que amb tant de lluc va incorporant al teatre català bocinets d'història escènica estrangera, proporcionant-nos nous i utilíssims elements d'estudi, que bé ens calen a tots els que volem que la cultura catalana siga quelcom més que una vana presumpció nostra (Carta del 19 d'octubre de 1909, Català, 1972, p. 1836).

La necessitat d'obrir-se a la cultura europea i d'anar traduint tot el que de nou i modern s'hi produiia havia estat des del tombant de segle una de les reivindicacions més constants dels ambients modernistes i havia afectat també el teatre (cf. Fàbregas, 1972, p. 118-119). Ja Alexandre Cortada havia cridat l'atenció, des de L'Avenç,7 sobre la urgència d'introduir models estrangers; però havia estat sobretot Adrià Gual, com ja és sabut, el qui havia intentat dur a terme un projecte de modernització de l'escena catalana de gran envergadura (cf. Gallén, 1986). Aquest ambient d'efervescència traductora devia tenir sens dubte una certa transcendència també damunt d'Oller, tot i que ell no compartia gens les idees i els models teatrals que els modernistes defensaven i dels quals es va preocupar de distanciar-se. És evident que el fet de traduir i d'assumir aquesta activitat com a tasca col-lectiva, tal com Oller fa a les Notes, és possible perquè les batalles de les joventuts modernistes havien aconseguit generalitzar una determinada mentalitat més enllà de les files del moviment. D’aquesta mentalitat i del nou clima teatral que es produeix arrenca l'aventura teatral d'Oller.

Pel que fa a la tria dels textos, Oller es va decantar cap a uns models, tot i que no sempre antagònics, molt diferents als que es van imposar al teatre català d'aquells anys. Amb tot, no eren de cap manera uns models que es poguessin arraconar com a rancis o vuitcentistes. De fet, la primera obra que Oller tradueix, el drama burgès de Giacosa Come le foglie, s'havia convertit en aquells moments a Itàlia en un gran èxit de públic (cf. Bisicchia, 1987) i havia consagrat el seu autor com a màxim representant d'aquest tipus de teatre de matriu verista, un teatre en el qual l'interès per una penetració psicològica més subtil dels conflictes interiors dels personatges es combinava amb un intent clarament pedagògic i moralista. Aquest drama, en què Giacosa indagava petites veritats, gens heroiques, de la vida quotidiana i on feia alhora una reconstrucció minuciosa d'ambients socials burgesos, va despertar molta adhesió també perquè les consciències trasbalsades per les experiències teatrals decadentistes el van acollir com «un soffio d'aria fresca, viva, restauratrice», tal com escrivia el crític Giovanni Pozza al «Corriere della Sera» l'1 de febrer de 1900, l'endemà de l'estrena milanesa (cf. De Rienzo, 1987). A Barcelona, l'obra es va estrenar en italià al cap tan sols d'un mes i mig, el 18 de març, durant la primera cam-

7. Amb els articles El teatre a Barcelona als núms. 9 (setembre de 1892) i 11 (novembre de 1892). 
panya de la companyia de Teresa Mariani. ${ }^{8}$ L'èxit va ser remarcable, com ho confirma el fet que fins al 1907 la van tornar a posar en escena també d'altres companyies italianes i que, dins del conjunt d'aquests repertoris, va ser una de les obres amb major nombre de representacions. La crítica que Josep Roca i Roca va dedicar a l'estrena de Teresa Mariani des de "La Vanguardia» (25 de març de 1900) ens recorda la lectura moralista que n’havia fet Pozza a Itàlia, si més no pels termes amb què situa l'obra en el panorama europeu. Roca i Roca, a partir de Come le foglie, destaca la bondat i l'especificitat d'aquest model de teatre psicològic representat per Praga, Giacosa i Rovetta en comparació amb el teatre francès i amb el teatre nòrdic. L'escola francesa és més amena, a la nòrdica hi domina el caràcter transcendent, "envuelto en misteriosas brumas", dels problemes socials i de consciència individual. En canvi, l'escola italiana "se destaca por su calor de humanidad, por la vigorosa concepción de los asuntos familiares, por la sobriedad de su desarrollo y por la firmeza que se observa en la pintura de los personajes». És a dir que Roca i Roca apreciava dels textos de Giacosa tant la defensa que s'hi feia dels valors de la família com la distinció clara i ferma entre personatges bons i dolents. Des d'una perspectiva anàloga, Josep Morató copsa, en ressenyar-la per a «La Veu de Catalunya» (19 de març de 1900), tots els aspectes moralistes de l'obra: l'abnegació del pare, la generosa comprensió del cosí, la victòria final dels bons, etc. En aquesta mateixa línia es pot col-locar el judici de Narcís Oller, el qual, a les seves memòries teatrals, en recordar la impressió rebuda per aquella representació de Teresa Mariani, destacarà, com a qualitats del text, el tractament psicològic dels ambients i el seu sentit moral i pedagògic:

me delectá aqueixa obra per la profunditat de sa psicología social y per la maravellosa transparencia ab qu'en ella's manifesten les ánimes y carácters de tots els personatges que l'autor hi posa en jòch (p. 1).

Cal llegir aquesta «transparència» també en oposició al misteri i a l'ambigüitat que envoltava molts dels personatges del teatre simbolista i decadent, cap al qual Oller adreça dures censures al llarg de les seves memòries.

Malgrat tot, també la crítica modernista va acollir favorablement l'estrena de Come le foglie, encara que no pas pels mateixos motius exposats per Morató o per Oller, sinó perquè hi trobava un tema molt apreciat pels sectors vitalistes: l'enfrontament, destinat al fracàs, d'homes faltats de voluntat i energia davant les lleis de la vida. La lectura que en va fer Emili Tintorer a Joventut, ${ }^{10}$ tot exagerant els suggeriments de Giacosa, acabava enfocant l'oposició entre els personatges com una oposició ideal entre ineptes i lluitadors, entre "voluntat atrofiada» i

8. Tot i que aquesta ni tan sols havia pogut assistir a les representacions italianes perquè havia estat treballant al Teatre Novetats des del 10 de gener.

9. Segons recullen Bonzi i Busquets (1995, p. 698), es van donar 32 representacions entre Barcelona i Madrid.

10. Any I, 6 (22 de març de 1900), p. 89-90. 
"voluntat ferma», entre impotència i força. ${ }^{11} \mathrm{I}$ justament per aquest motiu, Tintorer, tot i definir l'obra en termes positius com un «drama exuberant, ple de vida, d'una observació serena y d'una sátira sangrenta», no va manifestar la mateixa adhesió per la resolució del conflicte, massa tranquil.litzadora i redemptora: «el desenllás trágich que casibé s'imposava, sembla qu'hagi espantat á l'autor, y sa fantasía li ha inspirat un medi de ferlo més consolador».

De tota manera, gràcies a aquesta doble lectura, l'una rigorosament moralista, l'altra apassionadament vitalista, hàbilment propiciades pel mateix autor, el drama de Giacosa va guanyar-se els favors d'un públic molt ampli i la traducció que en va fer Oller per a la "Biblioteca Popular de L’Avenç» (1905) va trobar una molt bona acollida i un director interessat a dur-la al teatre en català, Adrià Gual, el qual va incloure l'espectacle dins de la programació del Teatre Intim. El contrast entre Gual i Oller, segons explica aquest a les seves Notes, es devia fer patent el dia de l'estrena, quan Oller, en veure durant la pausa després del primer acte el decorat triat per al segon, va obligar Adrià Gual a substituir-lo immediatament. I és molt probable, tenint en compte els detalls que Oller ens assenyala a les Notes, que la divergència en la reconstrucció de l'ambient procedís més aviat d'una diferent concepció de l'obra que no pas d'una mera qüestió escènica i dramatúrgica. L'escena que Adrià Gual havia imaginat radicalitzava els tons i els contrastos, i d'aquesta manera no respectava, als ulls d'Oller, les lleis del decor burgès. ${ }^{12}$ Els dos enfocaments que hem anat veient no acabaven d'encaixar damunt l'escenari.

A banda de l'incident amb Gual als bastidors del Teatre Principal, Com les fulles va agradar molt al públic i va rebre bones crítiques, la qual cosa, com ja hem vist, va animar Oller a seguir traduint obres de Giacosa, concretament els Tristos amors, un drama centrat en el tema de l'adulteri, i El més fort, en què es retrata un conflicte entre pare i fill com a resultat de dues concepcions ideològiques diferents. Abans que aquestes dues versions sortissin publicades a la

11. És tan forçada la seva interpretació que fins i tot acaba recreant un diàleg del personatge de Màxim per fer-lo més ajustat als significats que hi vol imprimir: «Trevalléu y lluytéu — dirá ell- qu'en el trevall y en la lluyta es ahont s'hi troba la vera forsa y la vera bellesa!». La paraula "lluita", que aquí connota la força d'aquest personatge com una combativitat rebel, no apareix mai, en canvi, en els seus discursos. Els personatges guanyadors de Giacosa no són pas rebels, sinó treballadors incansables i honestos, sovint poc lluïts.

12. Així ho comenta Oller, deixant veure a la vegada la natura ideològica del conflicte: «El disbarat més gròs qu'anava a ferse era'l de presentar el mobiliari triat pel Sr. Gual: una taula de pí pobríssima y, per buffet ó tinell, un'altra de la meteixa calitat flanquejada per dos llistons verticals que sosteníen uns fils-ferros dels que penjaven pahelles y caceroles de lláuna. / Per Deu, amich Gual: què fá? Que no ha llegit l'obra? Ni una miseria aixis la trobaría vostè en el recó mes infelís de Suissa, ni en Giacosa ens pinta a la familia Rosani a l'última pregunta, ni la generositat d'en Máxim podría may permetre que'ls parents, qu'ell tant estima, visquessin tan pobrament. / Era evident qu'en Güal, no l'havía llegida. El deliquacent de fí de sigle se devía donar a menos de llegir un'obra d'un neula com el Sr. Giacosa! Y no’s prengui això a calumna apassionada. Aquí tots els soidisants intelectuals d'aquell temps desdenyaven olímpicament tot lo que no'ns vingués del Nort ó que no portés almenys les firmes d'en Meterlinch y d'en D'Annunzio» (p. 4). 
col-lecció popular de L’Avenç, respectivament el 1907 i el 1908, Oller va dedicar les vacances d'estiu de 1907 a traduir una altra novetat del teatre italià: Papà Eccellenza de Girolamo Rovetta, un autor de consum en aquells anys a Itàlia. Papà Ministre, que es va estrenar al Principal el febrer de 1908, va tenir un èxit estrepitós als escenaris catalans i va acabar reblant la fama de traductor teatral que Oller s'havia guanyat amb Giacosa. Es tracta, sens dubte, de la temporada més intensa i amb més satisfaccions de la seva dedicació al teatre. ${ }^{13}$ Poc més d'un mes abans, cap a finals d'any, s'havia posat en escena també Tristos Amors, que ja es coneixia en la versió italiana de Teresa Mariani. La iniciativa havia estat de la companyia del Teatre Romea, on treballava, entre d'altres, una encara no consagrada Margarida Xirgu que va ser la protagonista de l'obra gràcies a la insistència d'Oller. La crítica més entusiasta va arribar de la mà de Josep Carner. En una carta publicada a Empori, "Lletra a D. Narcís Oller", Carner felicitava el traductor per haver escollit «l'amable Giacosa, per naturalitzar-lo català». ${ }^{14}$ Carner ara descrivia l'autor italià des d'una nova perspectiva. Tot recuperant el motiu de la comparació amb els models nòrdics, valoritzava en Giacosa la dimensió solar i mediterrània de les situacions $\mathrm{i}$, sobretot, admirava la seva estètica dels sentiments, ja que li devia semblar en sintonia amb l'esperit noucentista. Segons Carner, tot i no ser Giacosa l'autor «més genial», es podia considerar el dramaturg que més convenia traduir al català perquè posseïa «una claredat, una serenitat, una gràcia humana, un sentit de proporció i d'equilibri, que a nosaltres, mediterranis, ens guanyen de preferència al llampec entre tenebres o a la perillosa floració dels abims». D'altra banda, un dels secrets de l'èxit de Giacosa havia estat el seu llenguatge impregnat de poesia. La poesia íntima i vibrant de les relacions familiars i de la vida quotidiana. Aquest to era el que probablement Carner va apreciar. Així que, encara que les idees teatrals d'Oller no acabaven d'encaixar ni amb els modernistes ni amb els noucentistes, la tria de Giacosa va acabar sent molt afortunada perquè el seu teatre es va revelar capaç de connectar amb sectors molt diferenciats.

La lletra de Carner es concloïa demanant a Oller que seguís traduint, per tal de retre un servei al país, «delicioses comèdies italianes». Fixem-nos que aquí Carner parla de "comèdies» i no pas de «drames»: probablement ja no devia pensar en Giacosa. Jo crec que Carner pensava, més aviat, en Goldoni, i ho crec sobretot perquè ja havia manifestat el seu especial interès per aquest autor: la primera vegada ho havia fet en un discurs pronunciat el gener de 1906, després que es representés per primer cop en català una obra de Goldoni, sota la direcció d'Adrià Gual i en traducció de l'actor Puiggarí; la segona, el març de

13. Al cap d'un mes de l'estrena, la revista De Tots Colors va dedicar a Narcís Oller la secció Els nostres artistas en caricatura del n. 10 (6 de març de 1908), p. 153-155. Les notes autobiogràfiques que acompanyaven la caricatura es tancaven amb una clara referència a la fama de traductor teatral adquirida: «l'autor de L'escanya pobres, la Febre d'or, Pilar Prim, etc., i traductor de obres tan remarcables com les de Giacosa i darrerament de Papà ministre, quin èxit m'ha rejuvenit y alentat».

14. Empori, 7 (gener de 1908), p. 5-7, ara reproduït dins Carner (1986, p. 64-67, citació p. 66). 
1907, amb un article escrit arran del segon centenari del comediògraf italià. ${ }^{15}$ El que més crida l'atenció, de fet, és que, en aquelles ocasions, Carner havia descrit el teatre de Goldoni en termes molt semblants als que hem vist aplicar a Giacosa. Fins i tot fa servir els mateixos qualificatius quan lloa, per exemple, la claredat de les seves obres, l'equilibri dels sentiments i l'amable psicologia dels caràcters, i recorre a les mateixes argumentacions quan el considera com «un autor excel.lent per a parlar a la gent catalana» (Carner, 1986, p. 52). Finalment, també havia assenyalat en Goldoni l'origen dels valors peculiars del drama modern italià. ${ }^{16}$ Desconec quins efectes devia provocar en Oller la lletra de Carner com també ignoro si es van produir o no altres contactes entre els dos escriptors sobre aquest tema. Tot i així, em sembla interessant subratllar aquesta coincidència: a finals de 1908 apareixia publicada la primera traducció que Oller va fer de Goldoni, El Vano, i a l'estiu d'aquell mateix any, durant les vacances a Puigcerdà, ja va quedar enllestida la segona, El sorruł benefactor, ${ }^{17}$ que es va editar l'any següent juntament amb l'acte únic L'Avar. Oller es decantava ara cap a un tipus de teatre que ja no podia oferir com a actual, però sí com a clàssic. No es pot descartar que confiés en un possible muntatge escènic, ja que després dels bons resultats obtinguts amb Giacosa, les seves traduccions teatrals ja eren pensades de cara a l'escena, tal com li escriu a Matheu a propòsit de Rovetta, Turguenev i Pauloski. El fet és, però, que aquestes comèdies goldonianes no es van arribar a representar, segurament perquè aquest model teatral, malgrat l'admiració de Carner i malgrat el seu valor de clàssic per damunt de les modes, no deixava de ser bon tros allunyat de les expectatives del públic.

Després de Goldoni, Oller no va traduir cap més comèdia italiana i, de fet,

15. El primer text a què em refereixo és la dissertació acadèmica El drama català modern, pronunciada a l'Acadèmia Catalanista de la Congregació Mariana el 24 de gener 1906. He pogut consultar una còpia de l'acta acadèmic gràcies a l'amabilitat de Jaume Aulet. El segon text és l'article El segon centenari de Goldoni, "La Veu de Catalunya» (12 de març de 1907), ara dins Carner (1986, p. 52-53. Sobre la revaloració que Carner fa de Goldoni cf. Aulet (1992, p. 334-346) i Gavagnin (1996).

16. L'article commemoratiu de 1907 s'acaba d'aquesta manera: «En l'ordre trascendental, ¿qui dubta que és gràcies a Goldoni que avui el drama modern, la comèdia moderna, floreix a Itàlia amb flexibilitats, galanies i transparències, que donen a l'obra teatral un valor d'humanitat, si menys imposant i simbòlica, més agradable i pietosa?» (Carner, 1986, p. 53).

17. Amb un títol encara provisional, però: «El Burbero benefico ja'l tinch traduhit; ja tinch acabada la tasca. Com mellor l'he anat veyent, més he cregut qu'en catalá ha de titularse El reganyós compassiu. El rondinayre, el mal-carat, el déspota, no'm semblan tan bé. De tots modos, encara veurém» (carta a F. Matheu de l'11 de setembre de 1908).

18. Totes tres comèdies havien estat representades en italià: Il burbero benefico i L'avaro per Novelli el 1894; Il ventaglio per Dora Baldanello el 8 de febrer de 1908. És més que probable que Oller les hagués conegudes per aquest canal.

19. Cal dir que El sorrut benefactor va ser posat en escena molts anys després per Adrià Gual en un circuit molt diferent: l'espectacle va ser representat per l'Escola Catalana d'Art Dramàtic Adrià Gual el curs 1917-1918 al Teatre Goya i el curs 1931-1932 a l'Ateneu Verdaguer (cf. Galí, 1984, p. 234-325) 
al cap de pocs anys, el 1913, abandonaria definitivament les traduccions teatrals. Els espectaculars èxits aconseguits amb Giacosa i Rovetta no s'havien tornat a repetir amb els drames d'autors russos, però també cal dir que les perspectives del teatre català havien canviat força. Amb la segona dècada del segle s'encetava un període de desorientació i de crisi que es va fer més agut encara durant els anys de la Primera Guerra Mundial, quan les companyies estrangeres, és a dir el canal més important de renovació, van suspendre les seves visites. L'activitat teatral de Narcís Oller cal explicar-la dins del marc molt peculiar que havia caracteritzat el tombant de segle. La voluntat d'una plataforma teatral moderna havia creat un terreny molt propici a experiències teatrals força eclèctiques, un terreny en què tenien cabuda tant Ibsen, Maeterlink i D’Annunzio com Giacosa, Rovetta i Goldoni.

\section{Cronologia de les traduccions de l'italià d'Oller}

1905 Com les fulles (Giuseppe Giacosa, Come le foglie, estrenada a Milà el 31 de gener de 1900), Barcelona: Biblioteca Popular de l'Avenç, n. 40. [Exemplar corregit per Emili Guanyavents per a les obres completes d'Oller conservat a la BdC (Biblioteca de Catalunya); aquest exemplar conté també algunes correccions autògrafes d'Oller].

Ressenyes: El Poble Català, 7 de novembre de 1905 (Joan Avinyó); Ilustració Catalana, 124 (15 de novembre de 1905), p. 670.

Estrenada al Teatre Principal el 16 de gener de 1906 dins les sessions selectes del Teatre Íntim d'Adrià Gual.

Ressenyes: «La Veu de Catalunya», 16 de gener de 1906 (Josep Morató); L'Esquella de la Torratxa, 19 de gener de 1906; Garba, 9 (20 de gener 1906), (Joan Blancas); Ilustració Catalana, 138 (21 de gener de 1906), p. 45 (Morera y Galicia).

Estrenada en italià al Teatre Novetats el 17 de març de 1900 per la companyia de Teresa Mariani.

Ressenyes: «La Veu de Catalunya», 19 de març de 1900 (Josep Morató); «Diari de Barcelona», 20 de març de 1900 (Trullol y Plana); «La Vanguardia», 25 de març de 1900 (Josep Roca y Roca); Joventut, 6 (22 de març de 1900), p. 89-90 (Emili Tintorer).

1907 Tristos amors (Giuseppe Giacosa, Tristi amori, estrenada a Roma en la temporada de Quaresma de 1887), Barcelona: Biblioteca Popular de L’Avenç, n. 68. [Exemplar corregit per Emili Guanyavents per a les obres completes conservat a la BdC; aquest exemplar conté també algunes correccions autògrafes d'Oller.]

Estrenada al Teatre Romea el 20 de desembre de 1907 per la companyia d'Ermengol Goula.

Ressenyes: «La Veu de Catalunya», 21 de desembre de 1907 (Josep Morató); Empori, 7 (gener 1908), p. 5-7 (Josep Carner); L'Escena Catalana, 232 (18 de març de 1911), p. 4 (ressenya a una representació al Círcol de Sans). 
Estrenada en italià al Teatre Novetats el 17 de gener de 1900 per la companyia de Teresa Mariani.

Ressenyes: «Diari de Barcelona», 18 de gener de 1900; Joventut, número antecedent (gener-febrer 1900), p. XXV-XXVI (Emili Tintorer); «La Veu de Catalunya», 19 de gener de 1900 (Josep Morató).

1908 Papà ministre. Drama en tres actes (Girolamo Rovetta, Papà eccellenza, estrenada a Roma el 1906), Barcelona: Ed. B. Baixarias, Biblioteca De Tots colors. Publicat abans per entregues a la revista De Tots Colors, 12-22 (20 de març de 1908/29 de maig de 1908). [Exemplar corregit per Emili Guanyavents per a les obres completes conservat a la $\mathrm{BdC}]$.

Estrenada al Teatre Principal l'1 de febrer de 1908 per la companyia d'Enric Giménez.

Ressenyes: «La Veu de Catalunya», 1 de febrer de 1908 (Josep Morató); «El Poble Català», 2 de febrer de 1908; De Tots Colors, 6 (7 de febrer de 1908), p. 93-94; L'Escena Catalana, 71 (8 de febrer de 1908), p. 3.

Estrenada en italià al Teatre Novetats el 12 d'abril de 1909 per la companyia de Ferruccio Garavaglia.

1908 El més fort (Giuseppe Giacosa, Il più forte, 1904), Biblioteca Popular de L'Avenç, n. 78. [Exemplar amb algunes correccions autògrafes d'Oller conservat a la $\mathrm{BdC}$.]

Ressenyes: De Tots Colors, 14 (3 d'abril de 1908), p. 216-217 (Atxa [Joan Oller i Rabassa]).

1908 El vano (Carlo Goldoni, Il ventaglio, 1765), Barcelona: Biblioteca Popular de l'Avenç, n. 86.

Primera i única representació en italià al Teatre Eldorado el 8 de febrer de 1908 per la companyia de Dora Baldanello.

1909 El sorrut benefactor/ L'Avar (Carlo Goldoni, Il burbero benefico, 1771 / L'Avaro, 1756), Barcelona: Biblioteca Popular de L'Avenç, n. 98. [Exemplar amb algunes correccions autògrafes d'Oller a la BdC.]

Ressenyes: De tots colors, 95 (29 d'octubre de 1909), p. 681-82 (Atxa [Joan Oller i Rabassa]).

Estrenada al Teatre Goya el 1918 per l'Escola Catalana d'Art Dramàtic Adrià Gual.

Representacions en italià. Il burbero benefico: al Teatre Principal el 12 de febrer de 1894 per la companyia d'Ermete Novelli. El mateix Novelli la va tornar a representar el 13 d'octubre de 1907 al Teatre Eldorado. L'avaro: única representació el 20 de febrer de 1894 al Teatre Principal per la companyia de Novelli. 
1930 Traduccions selectes (Teatre), dins les obres completes d'Oller editades per Gustau Gili (vol. XII). Conté les següents obres: Papà ministre, Tristos amors, Com les fulles, El pa d'altri (Turguenev), El darrer hoste (Schmidt). El volum apareix pòstum, però havia estat preparat per l'autor.

\section{Referències bibliogràfiques}

AULET, Jaume (1992). Josep Carner i els orígens del Noucentisme. Barcelona: Curial/ Publicacions de l'Abadia de Montserrat.

BisiCCHIA, Andrea (1987). «Per una storia delle messinscene delle commedie di Giacosa». A GiACOSA, Giuseppe. Teatro, p. 179-183. Milano: Mursia.

BONZI, Lidia; BUSQUETS, Loreto (1995). Compagnie teatrali italiane in Spagna (1885-1913). Roma: Bulzoni.

CARNER, Josep (1986). El reialme de la poesia. A cura de NARDI, Núria; PELEGRí, Iolanda. Barcelona: Edicions 62.

CATALÀ, Víctor (1972). Obres completes, Barcelona: Selecta.

CORRETGER, Montserrat (1995). Alfons Maseras: intel.lectual d'acció i literat. Barcelona: Curial/Publicacions de l'Abadia de Montserrat.

De RienZO, Giorgio (1987). Introduzione. A GiACOSA, Giuseppe. Teatro, p. 5-9. Milano: Mursia.

FÀBREGAS, Xavier (1972). Aproximació a la història del teatre català modern. Barcelona: Curial.

GALÍ, Alexandre (1984). Història de les institucions i del moviment cultural a Catalunya 1900-1936. Barcelona: Fundació A.G.

GalléN, Enric (1986). "El Teatre». A RiQuer; COMAS; MOlas. Història de la literatura catalana, VIII, p. 379-448. Barcelona: Ariel.

GAVAGNIN, Gabriella (1996). "Il teatro goldoniano nella Catalogna del primo Novecento». A RODRÍGUEZ, Inés; LEAL, Juli (eds.). Carlo Goldoni: una vida para el teatro, p. 139-153. Valencia: Universitat de València.

OlLER, Narcís (1962). Memòries literàries, Barcelona: Editorial Aedos. 